\title{
Problematizing the absent girl: sport as a means of emancipation and social inclusion
}

David Ekholm, Magnus Dahlstedt and Julia Rönnbäck

The self-archived postprint version of this journal article is available at Linköping University Institutional Repository (DiVA):

http://urn.kb.se/resolve?urn=urn:nbn:se:liu:diva-15.3841

N.B.: When citing this work, cite the original publication.

This is an electronic version of an article published in:

Ekholm, D., Dahlstedt, M., Rönnbäck, J., (2019), Problematizing the absent girl: sport as a means of emancipation and social inclusion, Sport in Society. https://doi.org/10.1080/17430437.2018.1505870

Original publication available at:

https://doi.org/10.1080/17430437.2018.1505870

Copyright: Taylor \& Francis (Routledge) (SSH Titles)

http://www.routledge.com/ 


\title{
Problematizing the absent girl: sport as a means of emancipation and social inclusion
} Ekholm, D., Dablstedt, M. \& Rönnbäck, J.

\begin{abstract}
Absence from sport participation among girls from ethno-cultural minorities is often highlighted as an inclusion policy challenge. Based on 35 interviews with community sports coaches, managers and partners, we explore how the absence of girls is problematized in four Swedish sports-based interventions, focusing on how problems, as well as the means and the ends of social inclusion, are articulated. The girls are assessed as being in need of social change due to their alleged social exclusion. Absence is explained by "patriarchal norms" as well as by the introvert conduct of the girls themselves. Girls-only sports activities performed by female coaches as role models are described as a way for girls to gain social inclusion and to become emancipated from subjugating norms. In conclusion, participation in community sport is highlighted as crucial for adopting powers of emancipation. A similar discourse could be recognized elsewhere, inside and outside the realm of sport.
\end{abstract}

\section{INTRODUCTION}

That is the biggest problem. They are nowhere. They are at home. (The manager, West City midnight-football)

The statement above was articulated by the manager of a sports-based intervention in a suburban area in Sweden, when asked about the presence or absence of girls in a sports-based intervention activity. The girls do not engage in sport. They are nowhere, or they are at home, or in any case, they are not at the sports site. The quote is illustrative of a wider discourse concerning the girls, particularly certain categories of girls, and the problem of their lack of participation in and their absence from sports (cf. Agergaard 2016; Walseth and Fasting 2004). This article deals with how representatives of a sports-based intervention perceive the absent girls as a problem, why the absence is a problem, and for whom and how the problem might be understood as well as dealt with. In this article, we examine four sports-based interventions -Football for inclusion, The Sport Program, East City midnight-football and West City midnight-football - conducted in three suburban "areas of exclusion", located in two mid-sized Swedish cities.

In recent years, there has been increasing political and media attention paid to segregation and social exclusion in the Swedish suburban landscape (Sernhede, Thörn and Thörn 2016). In this sense, the urban peripheries, and particularly the youth in the suburbs, have been placed in the spotlight of problematizations and subjected to a wide range of social and welfare interventions, targeting specific so-called areas of exclusion (Dahlstedt and Lozic 2017). In the last decade, economic inequality in Sweden has increased rapidly; this is evident with respect to social and ethno-cultural as well as spatial segregations (Salonen 2011; Statistics Sweden 2014; Stigendal 2016). The concentration of residents with migrant backgrounds as well as with poor financial situations is steadily increasing in areas of public housing in suburban residential areas (Andersson 2013). In this context, sport has been on the agenda for policy attention, particularly with respect to social inclusion, and has been viewed as an instrument to promote social change, for instance in Europe and in the UK (e.g. Collins and Haudenhuyse 2015) as well as in Sweden (e.g. Fundberg 2017). Symptomatically, the Council of the European Union proclaimed 2010 as the European Year of Social Inclusion, articulating sport as a notable means of promoting inclusion, and particularly highlighting the dimensions of gender inclusion and exclusion (cf. Collins and Haudenhuyse 2015). In relation, there is a notable distinction between promoting 
policies for social inclusion in sport and promoting policies for social inclusion through sport (Collins and Haudenhuyse 2015). Importantly, participation and inclusion in sport are seen as necessary for utilizing sport as a vehicle for inclusion in communities and in society (through sport) in a broader sense. Sports-based interventions are thus based on inclusion in sport to make possible social inclusion through sport (Collins and Haudenhuyse 2015). Accordingly, reaching out to the absent youth and including them in sport activities is encompassed by a grander scope: to make social inclusion in Swedish society possible (cf. Ekholm and Dahlstedt 2017).

Altogether, this addresses the question of who participates (and who does not participate) in sports activities and thus who might become eligible for social inclusion intervention. The levels of participation in doing sport, and even the absence of girls, particularly from ethno-cultural minorities, has been noted (Long et al. 2009) and highlighted as a challenge for policy-makers (Walseth and Fasting 2004), for instance in Sweden (Fundberg 2017). Consequently, the absence of girls from sports activities becomes a problem which is noted widely both in social policy debate and in the research literature. If participation in sport is seen as a pathway to participation in society then the absence of girls from sport is a problem - not only for sport, but even more for society at large.

Informed by an approach to problematization, and with a focus on the representation of problems and the governing interventions that are made possible, we explore in this article how the absence of girls is constructed and represented as a problem by community sports coaches, managers and partners who are involved in and who conduct four sports-based interventions in Sweden. More precisely, we address the following questions: (1) How is the absence of girls problematized and explained in relation to the sports-based interventions? (2) How are girls made governable by means of such problematization? (3) How are the anticipated ends of the sportsbased interventions articulated and by which means should these ends be pursued.

\section{RESEARCH CONTEXT}

Internationally, a number of studies have focused on young women with migration experiences and their relationship with sports (cf. Agergaard 2016; Walseth and Fasting 2004). However, in Sweden there is a lack of research that focuses specifically on girls' participation in sport - for instance, girlhood scholars tend to ignore sports activities and sport scholars tend to neglect girls (Rönnbäck 2015). In this section, we overview previous research on sports-based interventions, particularly with respect to girls and their presence at and absence from sports activities.

Moreover, we elaborate on how existing research provides a point of departure for the approach adopted in this article. In addition, we highlight the empirical and theoretical contributions made in relation to this research field.

\section{Sports-based interventions: a means of making social policy}

Sport is assumed to activate citizenship and a sense of community and, therefore, has gained recognition in various policy areas in recent decades (Coakley 2011; Coalter 2007). Not least, sports-based interventions have been directed towards urban areas of exclusion (e.g. Bustad and Andrews 2017; Collins and Haudenhuyse 2015; Kelly 2011) and towards the inclusion of migrants (Agergaard, Michelsen la Cour and Treumer Gregersen 2015; Forde et al. 2015; Long, Hylton and Spracklen 2014; Spracklen, Long and Hylton 2015), involving civil society actors in welfare provision (Agergaard 2012; Ekholm 2016). Notably, participation in sport has been recognized as a path to inclusion (e.g. Vandermeerschen and Scheerder 2017). As Hartmann (2016) notes, youth residing in urban areas of exclusion are perceived as being in need of sports participation by means of inclusion in sport. With respect to the rationale of such an intervention, sport is assumed to promote opportunities of social mobility, as an activity for empowerment, or at least to divert youth from delinquency. Sports participation may also facilitate individual learning of life-skills (Danish and Nellen 1997; Gould, Flett and Lauer 2012) 
and promote empowerment (Lawson 2005) and the development of social capital (Harvey, Lévesque and Donnelly 2007; Nicholson and Hoye 2008). Moreover, sports participation can be an activity for building community bonds (Crabbe 2007). However, such activities have been observed to reach out primarily to boys and young men (cf. Hartmann 2016). Although, through the focus on the role of sport in promoting social inclusion, ideals of integration have been noted to imply assimilation of the cultures and norms of mainstream society (cf. Ekholm and Dahlstedt 2017; Forde et al., 2015), thus reinforcing racial hierarchies and stigmatizing the already excluded youth (Hylton 2011; Long, Hylton, and Spracklen 2014; Spaaij et al., 2016). In addition, it has been noted that children with migrant backgrounds have been included as the subjects of intervention in sports activities rather than as regular members of voluntary sports clubs in civil society (Agergaard, Michelsen la Cour and Treumer Gregersen 2015). From a critical point of view, researchers have stressed that sports-based interventions often fail to address, and, rather, mask racial and ethnic inequalities, gendered power relations and class structures (Coakley 2011, 2015; Hartmann 2016), as well as divert attention from the processes of social exclusion that such programs are designed to target (Collins and Haudenhuyse 2015). Moreover, sports-based interventions aimed at social inclusion are heavily imprinted with the ideals of masculinity, and implicitly target the inclusion of marginalized boys in sport and society, thus potentially further marginalizing girls (Kelly 2011).

\section{Absence of girls in sports research}

Although research on girls in sport, with respect to social exclusion, is not a major focus in the literature, some notes have been made underscoring some important points of recognition.

Research on this matter often has an obvious problem orientation, highlighting the social barriers and cultural norms that hinder girls with migrant backgrounds from inclusion in sport. In order to explain the lack of participation of minority girls, Strandbu $(2002,2005)$ highlights both the practical conditions for girls who need and want to prioritize school work and hanging out with friends rather than to participate in sports, and the economic conditions, noting that girls with migrant backgrounds often come from low-income households and lack social networks connected to people involved in sports. A variety of other studies have highlighted the importance of cultural norms and cultural differences. For instance, it is argued that within some communities participating in sport is seen as not respectable for women. Furthermore, organizational conditions, such as gender-integrated activities with certain rules concerning outfits and conduct, may be seen as an obstacle for some girls. For instance, cultural norms are said to be manifested through social sanctions from parents and other cultural gate-keepers (Ahmad 2011; Kay 2006; Walseth 2006; Walseth and Fasting 2004; Walseth and Strandbu 2014). However, minority girls are not passively subjected to such cultural norms, but rather they actively negotiate their identities in relation to such norms (Agergaard 2016; Kay 2006; Ratna 2011; Strandbu 2005). The complex of cultural norms and identity formation together make some girls not want to participate, while others are not allowed to participate (Walseth 2006). Additionally, many girls with migrant backgrounds who participate in sport do so because they are offered girls-only activities (Andersson 1999; Amara and Henry 2010). Notably, it is possible to consider (cf. Fielding-Lloyd and Meân 2008) and to arrange activities only for girls (Walseth 2008). If sports activities should be viewed as a means of integration and inclusion, the participation of minority girls is essential (Walseth 2008; Walseth and Fasting 2004). Accordingly, activities need to be arranged to make their participation possible (Walseth 2016).

Following Raval (1989) and Bradbury (2010), we argue that there is a need for research that focuses on external conditions, such as institutionalized sexism and racism, as well as focusing on the importance of class, rather than just limiting the analysis to the internal cultural norms of minority groups. In this article, we want to empirically highlight how minority girls' situations within sports-based interventions are portrayed in a context of suburban areas and social exclusion in Sweden. For our theoretical approach, we want to shift the focus from approaching 
the girls' absence as a problem per se, and from identifying the barriers that exclude girls from participation, to focusing on the discursive processes that construct absence as a problem that needs to be responded to. This is important because how problems are represented enables certain governing interventions.

\section{THEORETICAL FRAMEWORK}

The empirical material described in this study consists of statements made by respondents in interviews. In this section, the theoretical and methodological framework we use in the analysis of the empirical material is presented. Here, we focus on the acts of governing and problematization as well as on the intersections of social exclusion, and we describe how these analytical concepts guide our analysis.

\section{Governing, problematization and intersections of exclusion}

Following Bacchi (1999, 2009, 2012), problematization is a key concept for understanding contemporary forms of governing and is used as an analytical approach in this article. In this context, problematization refers both to the object of interrogation and to the methodological approach of examination. In this article, policies and statements are the objects of interrogation. They are viewed as discourses that animate social problems. This process is referred to as problematization, and it is in this meaning the concept is used in our analysis. Social policy and interventions should not only be treated as responses to pre-determined conceptions of social problems. Instead, social problems are represented and embedded in the ways in which social policy is articulated. Accordingly, governing practices and policy articulation are both seen as problematizing activities. Social policy, in this sense, need not be delimited to official governmental policy documentation, but rather as articulation of measures promoted by any governing agency (Bacchi 2009). In this article, this means that, in practice, articulations made by coaches and managers conducting the sports-based interventions make policy (cf. Ekholm and Dahlstedt 2017).

Furthermore, problematizations are formed at intersections between a range of categories and distinctions (cf. Hankivsky et al. 2012). An intersectional perspective makes it possible to approach gender as being intertwined with age, and with ethno-cultural and socio-economic dynamics. Analysed alone, each categorization could only provide limited understanding, and risks neglecting how distinct categories intersect and reinforce each other (cf. de los Reyes and Mulinari 2005; Lykke 2010). In line with such an approach, the concepts of racialization and racialized subjects refer to processes that construct differences on the basis of racial, ethno-cultural and/or religious categorizations, in relation to a certain norm (cf. Miles and Brown 2003; Goldberg 2009). In these processes of constructing differences, certain (racialized) subjects are positioned as deviating in relation to notions of "national belonging", which in this context is conceptualized in terms of Swedish-ness. Accordingly, a problematizing approach provides this study with tools for examining how such distinctions and categories are constructed and, moreover, for examining how the forms of governing are made possible (Bacchi 2009).

\section{METHODOLOGICAL CONSIDERATIONS}

Based on the article's point of departure presented in relation to the research context, and with respect to the theoretical framework elaborated above, we present the empirical material examined and the procedures of the analysis we used.

\section{Empirical material: the four sports-based interventions}

The four sports-based interventions we examined have similar objectives aimed at promoting social inclusion, but they target different, although overlapping, age-groups, and are conducted through different forms of public-private partnerships. Football for inclusion is conducted jointly in 
East City by three local sports associations in partnership with local schools and the municipal administration. Financially, the program is supported by public funding but also by charity organizations and sponsorships. Its aim is to "improve children's social and communicative competences and contribute to social inclusion, [to] activate children and youth [and to] facilitate friendship between children from different cultures". In this intervention, children aged 8 to 12 are invited to play football during school and during after-school activities. The Sport Program, also in East City, is conducted by a social entrepreneur in partnership with local schools and the municipal administration, as well as with coaches from local sports clubs. The program is financed primarily by public funding but is also supported by private sponsors. The aim of the program is to "reach out to children who are not active, $[. .$.$] gather up all youths in the risk zone,$ [and] coach, educate and guide them to a better future". In this program, children aged 11 to 16 are provided with opportunities to do a wide range of sports during school and after school, as well as in the holidays. The program started in the city that we study here but has recently spread to five other cities. Midnight-football is organized in both East City and in West City. In East City, the program is conducted by two local sports clubs, who are also involved in Football for inclusion, in partnership with a national, corporate social responsibility and charity-foundation specialized in setting up sports-based social interventions. The activities are supported by the municipality but funded primarily by local sponsors and sponsors within the national foundation. In West City, the program is conducted by a local sports club in partnership with the aforementioned foundation. Activities are supported primarily by local sponsors and by the partners within the foundation. The national foundation describes the goals in terms of "promoting integration through sport" by means of providing opportunities for youth "to develop a sense of responsibility and participation in society as well as employability [...], to prevent social exclusion [and] to contribute to crime reduction". Similar activities are carried out with the foundation as a partner in ten other cities. The activities consist of organized, yet spontaneous, indoor, five-a-side football games on Saturday nights from 20:00 to 24:00, which are open primarily to youths between 12 and 20 years old.

The different programs do not formally collaborate with each other. However, the Sport Program and Football for inclusion are performed in the same area as one of the midnightfootball programs and partly with the same sports clubs involved. Moreover, a few of the coaches are involved in more than one program. The two midnight-football activities are closely related to each other through the foundation. All programs have been nominated for, and have been awarded, prizes for their community work, and they have been repeatedly reported on in local and national media. Notably, each program respectively describes reaching out to and involving girls as a problem. Particularly, this is the case for the midnight-football programs which target older youths. The Sport Program and Football for inclusion reach out to girls more easily as they are formally partnering with the local schools, but in spite of this, reaching out to girls and involving them in sport participation is still viewed as a challenge.

The empirical material analysed in this article consists of statements articulated by coaches, managers and partners from all four programs. These statements were obtained through 35 semistructured, in-depth interviews conducted from 2013 to 2017. All interviews were transcribed verbatim. Questions posed in the interviews concerned the interventions in particular, and about sport as a means of social inclusion in general. Particular focus was on questions about youth participation and non-participation in the interventions, challenges in reaching out to marginalized youth and about the ways of organizing the activities. One recurring topic concerned the participation of boys and girls: specifically highlighting the explanations for the absence of girls. Notably, the variety of respondents involved in the different interventions and engaged in various roles in the practices, articulated similar rationales and narratives concerning sport's role as a means of social inclusion. The respondents also articulated the absence of girls as a major challenge and future tasks of the interventions. The overwhelming majority of 
respondents were men. In fact, only five women were included, of whom three had positions distant from the actual activities (two municipal civil servants and one financial sponsor), and two were sports coaches (in the Sport Program and in Football for inclusion). When conducting the interviews, we adhered to ethical guidelines concerning informed consent and anonymity as well as the option to cease participation at any time (cf. Swedish Research Council 2011). The names of the intervention programs and the respondents have been kept confidential.

\section{Analysis procedures}

The analytical approach to problematization adopted in this article means scrutinizing the premises on which the discourse is based and investigating the kind of governing actions enabled. In order to understand how the means of governing are made possible, the representations of social problems and the processes of problematization need to be examined (Bacchi 2009). Our analysis procedures were guided by the theoretical framework and focused on the process of problematization, taking the intersecting dimensions of exclusion into consideration. First, statements were thematically sorted into broad categories of problems and solutions. Based on these themes, certain regularities in statements were highlighted. One regularity, focusing on how the girls themselves and their specific living conditions were constructed as problematic (the problems), concerned how they were seen as being in need of social change and being represented as passive and subjugated. Regularities on how the objectives of inclusion are formed in discourse (the ends) concerned how sport was seen as a form of path away from exclusion and subjugation, towards inclusion and emancipation. A regularity on how (by what means) such desired objectives were perceived as being possible to attain concerned the use of role models as facilitators of social inclusion, and the importance of girls-only activities. Second, interpretation of the statements was guided by the theoretical concepts introduced in the previous section. In this sense, the analysis provides a framework for an analytical and perspectivist "interpretation of interpretation" (cf. Bacchi 2009; Ekholm 2016).

In conclusion, the framework outlined here makes it possible to analyse how certain girls and their living conditions are problematized and made governable in relation to a range of intersections of exclusion. The framework also makes possible to analyse how social policy in practice is developing to promote social inclusion through sport, seeing that the girls are constructed as a group in need of intervention. Accordingly, it is the discursive processes that construct absence as a problem that are highlighted in our analysis.

\section{RESULTS OF THE ANALYSIS}

In this section, we analyse how girls are represented as passive and absent from sport practices. The analysis is structured in four sections. Statements demarcating the subject of intervention (first) and defining the problems (second) are scrutinized, as well as the ends (third) and the means (fourth) of intervention and social change. Girls are represented as being both in need of intervention and as victims of "patriarchal cultures". Such problematization makes these girls the targets of certain interventions which focus on emancipation and empowerment, and which sport participation is assumed to provide, not least by means of facilitating women role models who reach out to the girls.

\section{A need being assessed}

It all starts with a need being assessed. With respect to the four sports-based interventions we observed, there are recurring narratives about how girls in the suburban areas of exclusion are not reached out to, or how they are perceived to be in need of social inclusion. The manager of the East City midnight-football program stresses that they "work really hard" reaching out to the girls, but it is "difficult, very difficult in these areas", and emphasizes that the suburban area of exclusion has a particular set of challenging conditions. He also stresses that failing to include 
girls is really the "weakness of the program". A similar way of pointing out that girls are a concern of intervention and social inclusion is illustrated in the following statement. Here, the manager of West City midnight-football describes how he perceives the need for particular interventions that target girls.

We saw the need because we didn't see the need, if you know what I mean. For the simple reason that there was no one requesting... No one asked, no one wondered, no one questioned and no one offered anything else. So, we saw, no, but wait... now this is strange. Shouldn't there be some upset girl here requesting and questioning, why aren't we invited here? (the manager, West City midnight-football)

In this quote, it becomes clear that the needs being assessed are linked with the absence of girls. The girls are neither heard nor seen. In terms of leisure-time activities, there is a lack of both demand and supply. No one in the residential area provides activities specifically targeting girls, and, according to the manager, the girls themselves do not request such activities. This is perceived to be a problem. Even in the articulation of needs, the absence of girls is problematized. Supposedly, if everything was as it should be, then at least girls would be inquiring about leisure-time activities. In the manager's view, it was a problem that no one asked about or requested midnight-football for girls. According to the manager, the girls do not express their voice or their need. Additionally, the manager seems surprised that the girls themselves do not articulate the need or request activities. Moreover, no other local agencies or actors appear to speak for the girls in this situation. In this narrative, it is up to the manager to assess the needs of girls, and the manager himself responds to this challenge and seeks to develop strategies for offering activities for girls.

Notably, girls within the suburban residential areas are demarcated as being in need of intervention. This is not based on how they articulate their situation themselves, but rather, based on how their lives and situations are perceived by others. Importantly, their need is assessed in relation to their lack of participation in sport, and also in relation to their perceived lack of inclusion in society. These points are elaborated on in the next section.

\section{Passive and absent: stereotypical problematizations of girls}

Problematizations involve notions of social change. Several of the respondents highlight that girls need to be reached out to in order to induce social change. For instance, the manager of West City midnight-football states that "after school, there are ninety-seven [percent] to three percent" boys in relation to girls present outdoors in the area, and "girls hardly even go to the store... and that is sad... and is something we try to change". Similarly, the manager of a health center sponsoring East City midnight-football who is also engaged in the program, stresses that the activities "are open for all [but that] experiences are that no girls are coming, perhaps because they are not allowed to do activities where there are boys participating". When reflecting upon the absent girls and their lack of involvement and participation in sport, two distinct types of problematization occur. On the one hand, the surrounding conditions concerning cultural norms and backgrounds are highlighted; on the other hand, girls themselves, with respect to their particular shortcomings, are pinpointed. Both these explicit problematizations put the primary focus on factors external to the sport activities being performed.

Recurrent in the statements we analysed are problematizations of other cultural norms and patriarchal notions which limit the girls' opportunities in life. In this context, culture refers to norms, made deviant, rooted in foreign countries, that become localized in the suburban areas of exclusion. These norms are thought to be brought to Sweden by parents and relatives. For instance, in the words of a recreation worker at a local school, it is the "prejudice and culture that they bring" and the expectations "from parents, fear and all that... patriarchy" that hinder the girls from participating in sport and in society in general. In the following excerpt, the manager of 
East City midnight-football expounds on the reasons why it is difficult for girls to engage in the activities.

It is more difficult for girls to be out late, harder... and then football and girls... I'm sorry but... this is a migrant-dense residential area... and among migrant parents it is not acceptable, they don't see things this way. So, these girls, when they ask their father and say that they want to go out and play football until late... to ten or twelve [at night]... it is not [possible]. (the manager, East City midnight-football)

Here, most profoundly, the specific characteristics of the suburban area are outlined as a framework for understanding the girls' situation and conditions. According to this statement, the residential area is migrant-dense and therefore seems to be characterized by a set of particular norms and restrictions about girls' participation in sport. These restrictions make it difficult for girls to stay out late when the sport activity is offered. In particular, in the above excerpt, fathers become representatives of the subjugating limitations of the girls' participation. For girls to be able to participate, it is perceived that they need permission from their fathers. Similarly, one of the sponsors of the midnight-football programs (a representative of an insurance company) describes the problem in terms of "girls are not even allowed to go out... there are actually cultures saying that... when school is over you come home, and then you stay indoors". In addition, the Sport Program manager points out that when the girls are at home, they are expected to "help around the house and stuff... and that it is perhaps a more traditional way of looking at it". Furthermore, such cultural norms in the statement are located, not only in the suburban areas of Swedish cities, but also in specific geographical areas abroad, such as Somalia and Bosnia, both of which are mentioned in excerpts from other interviews.

The conduct of boys and girls are problematized in different ways. They are both problematized as destructive, but in highly different ways. When boys need to be reached out to through sport participation, it is because of their extrovert and destructive manner and conduct. Their actions and energies need to be channelled and directed in a more productive way. Girls, in contrast, are described not in terms of their activity and agency, but instead, they are perceived as introvertly destructive, passive and sitting at home. In the following excerpt, the manager of West City midnight-football describes the multi-dimensional problem of the girls' conduct as well as their absence.

The problem is that boys are extrovert and destructive. The girls are introvertly destructive, that is, inward-acting. [...] It's very few girls out selling drugs. And it's very few girls involved in violence and stuff like that. [...] There are many others... feeling bad and going to psychologists and staying home, and they use drugs a few of them. [...] The girls set up their own barriers, "I'm not good enough, I don't fit in here...". Not like boys. For boys, it's much like to be seen and heard, that I'm the biggest and the best... and a need of affirmation. [...] But girls have a tendency to [...] minimize themselves and even diminish their friends in a whole other way. It must be some norm. (the manager, West City midnight-football)

In contrast to the boys, the girls are characterized here as problematic due to their selfdestructive conduct, in terms of introversion, lack of self-confidence and their self-regulation. Such conduct is described as the opposite of being seen and heard. Instead, destructive forces are directed inwards, and, according to the manager, this makes the girls particularly hard to reach out to and deal with. In relation to the barriers set by external forces such as parents, the manager's quote describes the internal forces of self-regulation and self-doubt of the girls as limiting their already limited opportunities, both to participate in sport as well as to be included in wider society. Symptomatically, such conduct is understood as being regulated by "some norm". One of the sponsors of the midnight-football program, a representative of the insurance company, also directed attention to the problem of the inward-directed focus among the girls: 
"Where do they direct their hatred and frustration? I believe they turn it towards themselves [...] how could they be reached out to?"

However, in the statements, the girls are talked about as being absent even though they might actually be present. In this case, their presence follows a pre-defined norm of conduct and appearance. In the specific case of midnight-football, girls can for instance be present as spectators, "they come there because there are boys there", as one recreational worker noted; "They watch, but they seldom play themselves". When the girls do play, on the other hand, their style of play is described as not serious enough. Here, the West City midnight-football manager states that "if they do play, it's most often fun and games, which makes the other girls not want to play...". Furthermore, the appearance of the girls - as spectators as well as players - is portrayed as deviating from the norm. As in this quote, in which the manager of West City midnight-football says of the girls: "They have just showered, put on their makeup and perfume, they are giggling and find it really fun kind of'.

To summarize, in a variety of different ways the girls and their living conditions are problematized. Most notably, the girls are portrayed as adhering to certain cultures that deviate from the norm, thus explaining their absence from sport as well as from society at large. In this way, the girls - absent as well as present - are identified as being in need of, and as the subjects of, intervention. Such a portrayal diverts attention from the arrangement of the sports activities as well as the norms and limitations within the sports activities themselves.

\section{Ends of inclusion: sport as a site of emancipation and social inclusion}

Given this problematization, in which girls and their living conditions are portrayed in various ways and constitute them as targets of intervention, certain sports-based activities are enabled. These interventions involve notions of social change; social change that has a certain direction. In the following two sections, we outline the ends and the means of the social change that is desired. Regarding the ends, emancipation from patriarchal rule and subjugating norms are a recurring notion in the statements analysed here. Importantly, emancipation can be viewed not only as an end in itself, but also as a prerequisite for social inclusion. In the following excerpt, one of the most dedicated sponsors of midnight-football - the representative of the insurance company, who at times has been involved in the activities on site - reflects on the potential outcomes of reaching out to girls and increasing the participation of girls in the sports activities.

What if you could get more girls there... playing... and the effects that would have. Both on how boys see girls and on how girls... like... they make space for themselves and develop courage to make that space. Because I think that [the East City manager] could see too... that if they only reach out and get the girls there, he will make it work. But there is a more serious underlying problem... it is not only that girls may be afraid but maybe more that they are not even allowed to leave their home after six at night... (the representative of the insurance company, sponsor of both midnight-football programs)

What is offered in this sports-based intervention, according to the statement, are opportunities to respond to the problems and challenges highlighted previously. Participation in the activities allegedly empowers girls with the courage to be active agents. This in turn may alter the ways boys perceive them. From being empowered and becoming active agents, there are three key steps - which manifest the direction of social change - on the route from patriarchal subjugation to inclusion in wider society. The first step is leaving home. In the statements analysed, home is the container of social exclusion, passivity, social control, dependency and patriarchal rule. The second step involves entering the sports setting. Accordingly, the sports setting should ideally offer space for the girls to be active and to participate in the same way as boys do. However, this has not proven to be the case, which, notably, is seen as a profound problem. The third step, consequently, involves a move from the sports setting into society at large. For this move to be 
possible, it is vital that girls develop powers and competences that are viable beyond the sports setting. In the above excerpt, powers and competences are conceptualized in terms of the "courage to make space". Also, in the words of the Sport Program manager, such powers are associated with "daring to show that even though you are a girl, you can do sport, and that there is nothing wrong with you". The powers demanded of, and possibly acquired in, this third stage could be understood as powers of emancipation: meaning emancipation from social exclusion and subjugation.

In this discourse, and recurrently articulated in the statements analysed, the sports-based interventions are artefacts, constructed to provide an environment for escaping social exclusion and for entering society as an included and emancipated equal. The four programs investigated in this study are, in various ways, designed to facilitate reaching this objective: to provide different means of responding to the problematizations outlined and to achieve the ends aimed for.

\section{Means of inclusion: modelling and facilitating social change}

In relation to the anticipated ends, the means to realize emancipation and social inclusion can presumably be attained in two ways: either by arranging separate activities for girls or by engaging female coaches as role models. In the first instance, there is certain potential for arranging activities in ways that enable girls to participate. In the statements analysed, there are descriptions of how gender-segregated sport activities are run and are presented as potential ways to involve girls. In the second instance, female role models, who are supposedly facilitating the move from exclusion to inclusion, are identified as being a decisive force in sports-based interventions.

In the interview statements, the presence of boys is perceived of as a barrier to the girls' participation. Therefore, gender-separate arrangements are strived for. Representatives of the programs, particularly with respect to midnight-football, regularly mention that they want to set aside separate hours for girls to engage in sport without boys being present. In the following excerpt, the manager of East City midnight-football introduces both strategies described above. He underlines the importance of female coaches as role models as well as girls-only activities. Notably, these factors are interrelated, highlighting how gender-separated contexts are perceived as being vital for reaching out and influencing girls.

I believe that, first and foremost, we need to have [female] coaches. We have a women's team [in our club] where we try to recruit coaches. That will be a key factor to... like... when we communicate that we start midnight football for girls, one hour. First, it should be for girls only. There have been occasional girls playing with the boys, but very sporadic. But if you can communicate that now it is one or two hours only for girls and there will only be female coaches... (the manager, East City midnight-football)

Beyond noting the importance of female coaches, the manager stresses the need to arrange activities for girls only. In his view, doing activities for girls separate from the boys' activities, and managed by women, is a key factor for reaching out and involving girls in sport. According to this reasoning, such an arrangement would be a way to facilitate the transition from staying at home to going out, and even to entering the sport activities. The manager remembered that there had been girls playing with boys on random occasions, but seldom and not at all regularly. By means of gender-separate arrangements, he hopes to create regularity in the girls' participation. Moreover, the separation of girls from boys makes it possible to regulate gender-specific conduct among both girls and boys. In this way, boys' attention is not diverted by "giggling girls" and could presumably be directed towards discipline and following rules, while girls are supposedly empowered and activated.

The most prominent means of reaching out to the girls, thus making empowerment and inclusion of girls possible, is described in terms of female coaches. The importance of such coaches is repeatedly emphasized in their capacity as role models. For instance, the Sport 
Program manager describes plans for the future to "make a real effort to hire more female coaches as positive role models coming to the area", because then it would be "ok to allow the daughters to go outside and do some activity and that [they would be in] no danger at all". In the sports-based interventions, the absence of female coaches is repeatedly highlighted. However, few women have been recruited as coaches. In the following excerpt, one of these coaches explicitly describes herself as being recruited as a role model for girls with migrant backgrounds.

They should be offered something to do and become interested in doing sports after school, and that way become integrated in society [...]. So, then [the organizer] called me up... because I'm a girl with a migrant background, I play football and also study to become a teacher... so, I really have it all. [...] We use football, because we are footballers, for creating an interest in sports and something to do after school, so that they don't just sit at home. [...] My role is to teach football, to be a role model. [...] I believe that my main role is... well... they, the girls, look up to me a bit. I'm a girl and play football, and... they think I'm clever and all that so they just want someone to look up to so they also know they can manage it. Increase their self-confidence, show that a girl can play football. It's not only for boys. And allow them a bit of space. Be there and push them. But as soon as they are older... if there are no girls there, then they don't want to come. They want someone who is like them. So, I believe it has a huge impact. That was in part why [the organizer] contacted me. Because people with migrant background play football and so... so, they have someone to relate to. [...] To show that you can play football. Many people with a migrant background have prejudices against girls playing sport in general. And helping them, well, if they wanted me to I'd be very happy to help them. If I need to speak to their parents, I can do that. In principle, I could do anything to help them, if they wanted to play football or something else. (sports coach, Football for inclusion)

In this excerpt, the female coach tells about how she was contacted and recruited because of her personal traits as being a female with a migrant background, as well as playing football and studying to become a teacher. She describes herself as a role model who girls can identify with and look up to. In this case, identity and identification are the keys to understanding the potential outreach. According to this reasoning, she and the children and youths who are targeted, belong to the same community; they are alike. The group of girls with migrant backgrounds is viewed as seemingly homogenous, and by being a representative of this group she sees herself as a legitimate role model. The rationality of the role model presupposes mutual identification: the role model identifies with the girls, and vice versa. This mutual relationship enables important gains for the girls in terms of empowerment, and increased self-confidence and assertiveness. According to this rationale, and being equipped with such powers and guided by the role model, it becomes possible for the girls to move from social exclusion to social inclusion. Thus, the role model acts as a conductor of social inclusion, leading the way with the three steps outlined previously. She has access to the home environments and has the potential to reach out to both the girls and their parents and to demonstrate the existence of leisure-time activities outside the household. She demonstrates that it is possible for girls in the residential area of exclusion to play football, and, moreover, she teaches and instructs them how to do it. In this way, she facilitates entry into and participation in the sports setting. Altogether, participation in sports activities introduces the girls to wider society and makes social inclusion possible.

In summary, the role model - from her own perspective - has the power to guide girls through the steps from exclusion and subjugation to the realm of agency and inclusion in Swedish society. Notably, the particular significance of female role models combined with gender-separate activities is seen as being decisive for making girls' participation in sport, as well as their social inclusion, possible. 


\section{DISCUSSION}

In this article, we have explored how the absence of girls from sport is problematized with respect to four sports-based interventions in Sweden. We have shown that girls in suburban areas of exclusion is categorized and assessed as being in need of social change due to the girls' lack of participation in sport and their alleged lack of inclusion in wider society. The problem of their absence from sports activities is explained in terms of differences in cultural norms as well as introverted and inward-acting conduct of the girls themselves. This problematization enables sports-based interventions as a means for the girls to avoid social exclusion and to enter society as included and emancipated equals. The rationale for achieving these ends is based on organizing gender-segregated, girls-only sports activities, supported by the presence of female coaches as role models.

Summarizing the main findings of the article, we can highlight a variety of dimensions of girl's absence in the statements. First, girls are absent from sports-based interventions. Even when they are present, girls do not adhere to the norms of conduct and appearance and are thus construed to be absent from serious participation. Second, with respect to the empirical material, there is an absence of the girls' own needs and requests, due to their alleged lack of voice. This means that their needs are most often assessed by the male coaches, managers and partners who run the programs, and who have not been responsive to other voices (if there were any). Third, female coaches are (more or less) absent from the interventions. At least, the absence of female coaches is regularly stressed and highlighted as a point of development and improvement. Accordingly, discourses on the absence of girls are not one-dimensional, but heterogeneous, highlighting several interrelated facets of exclusion. These absences are formed at the intersections of gender, age and ethno-cultural background. Throughout the analysis, girls - and particularly girls categorized as migrants or with migrant backgrounds - are associated with a variety of problematizations, identified as being in need, and concomitantly made governable. Their multifaceted positions as young, ethno-culturally different girls differentiates them from what is perceived as normal. Though what actually constitutes this normality is quite elusive and is most notably defined in relation to the problematized categorizations and conducts.

In this article, we have spotlighted the situation of girls in suburban areas in Sweden, or at least we have shown how this situation is understood by managers, coaches and partners engaged in setting up sports-based interventions in Sweden. This is important, not least when considering that the situation of girls has long since been neglected in policy-making as well as in research on sports and social policy, particularly since sports-based interventions are becoming a more common feature in the social policy repertoire in Sweden as well as in other parts of the world. Furthermore, our analysis has focused on problematizing rather than uncritically adopting and reproducing certain representations of social problems. Specifically, the article has provided an alternative to current problematizations of the absence of girls in sport, addressing the formative (discursive) processes which construct the representation of these problems with a focus on how they are formed and what such a formation makes possible in terms of governing interventions. We believe this is important because such representations are a common point of recognition, taken for granted not only in sports-based activities such as those analysed in this article, but also in policy-making and research.

However, the specific problematization of the absent girl in quite stereotypical terms, as highlighted in this article, is not exclusive to this particular investigation. Similar patterns of gender stereotyping can be recognized in a variety of other contexts. Within the realm of sport, the participation of girls has historically been seen as problematic in relation to predominant notions concerning gender (cf. Hedenborg and Pfister 2017; Svender 2012), particularly in team sports such as football. This is initially due to the norm-breaking participation of girls, with sport being a profoundly male/masculine arena (cf. Tolvhed 2015), and then later, due to their lack of 
participation or reluctance to take part in the activities (cf. Fundberg 2017). However, throughout history, it is not all girls who are problematized in the same ways. As evident in this article, in Sweden today, it is the intersections of gender, age and ethno-cultural background that define a specific category of girls as a subject of a governing intervention: the racialized girl from a suburban area of exclusion. This specific category is constructed as a singular collective of subjects that shares characteristics of deviancy, exclusion and subjugation, as defined by their belonging to a cultural group. One of the main features of this discourse on cultural belonging concerns racialized gender stereotypes, where girls are portrayed as subjugated by cultural norms and rules as well as by gendered notions of introversion and passivity. Looking outside the realm of sports, similar discourses on the problems of exclusion and absences of "the migrant girl" have been highlighted as part of mainstream media and policy discourse in Sweden as well as in other countries (cf. Brune 2004; Carbin 2010). In such discourses, "the migrant girl" has been represented as an object of rescue or in need of help to escape patriarchal traditions and rule (cf. Tigervall 2005; Mulinari 2014). Even though it is not regularly made explicit in the statements analysed in this article, there is a parallel between the descriptions of the girls as being subjugated and the wider discourses on Swedish gender equality, according to which migrants are problematized in terms of patriarchal norms and traditions (cf. Larsson 2015). At the same time, there is also a parallel with the wider problematization of girls and women in general, in sports as well as in society at large. Regularly, girls and women have been - and are still being - described as deviating from the established norms of a masculine society. In this sense, throughout a variety of historical and contemporary contexts, girls and women have been seen as problematic and thus in need of certain measures of social change (cf. Bacchi 1999; Eduards 2012).

Based on the analysis and the discussion above, some questions are raised that still need to be addressed. One question that has not been the focus of this article, but could provide important insights into the question of girls' absence, concerns the voices of the girls themselves: how girls articulate their desires and needs regarding participation, not only more broadly in sport and leisure-time activities (cf. Agergaard 2016; Knez, Macdonald and Abbott 2012), but also with regards to how they perceive their living conditions at large? Furthermore, considering the inequalities on the basis of race, ethnicity and, not least, gender, structuring sports activities even those with social objectives (cf. Hartmann 2016; Kelly 2011) - it is reasonable to question the use of sport as a means of social inclusion of girls and to question how it was promoted in the first place. Given that sport is far from an inclusive arena, but rather a male bastion coached and managed, more or less exclusively, by men, for men - such a concept could be considered a contradiction in term.

\section{REFERENCES}

Agergaard, S. 2012. "Governing integration through sports. A case study of civil society involvement in welfare policy". Nordic Journal of Migration Research 2 (1), 26-34. doi: 10.2478/v10202-011-0024-y

Agergaard, S. 2016. "Religious culture as a barrier? A counter-narrative of Danish Muslim girls' participation in sports". Qualitative Research in Sport, Exercise and Health 8 (2): 213-224. doi: 10.1080/2159676X.2015.1121914

Agergaard, S., A. Michelsen la Cour, and M. Treumer Gregersen. 2015. "Politicisation of migrant leisure: a public and civil intervention involving organised sports”. Leisure Studies 35 (2): 200-214. doi: 10.1080/02614367.2015.1009848

Ahmad, A. 2011. "British football: where are the Muslim female footballers? Exploring the connections between gender, ethnicity and Islam". Soccer \& Society 12 (3): 443-456. doi: 10.1080/14660970.2011.568110 
Amara, M. and I.P. Henry. 2010. "Sport, Muslim identities, and cultures in the UK, an emerging policy issue: case studies of Leicester and Birmingham”. European Sport Management Quarterly 10 (4): 419-433: doi: 10.1080/16184742.2010.502743

Andersson, M. (1999) “'All five fingers are not the same'. Identity work among ethnic minority youth in urban Norwegian context”. PhD diss., University of Bergen.

Andersson, R. 2013 "Reproducing and Reshaping Ethnic Residential Segregation in Stockholm". Geografiska Annaler, Series B, Human Geography 95(2): 163-187. doi: 10.1111/geob.12015

Bacchi, C. 1999. Women, Policy and Politics: The Construction of Policy Problems. London: SAGE.

Bacchi, C. 2009. Analysing Policy: What's the Problem Represented to Be? Frenchs Forest: Pearson.

Bacchi, C. 2012. "Why study problematization? Making politics visible". Open Journal of Political Science 2 (1): 1-8. doi: 10.4236/ojps.2012.21001

Bradbury, S. 2010. "From racial exclusions to new inclusions: black and minority ethnic participation in football clubs in the East Midlands of England". International review for the sociology of sport 46 (1): 23-44. doi: 10.1177/1012690210371562

Brune, Y. 2004. "Nyheter frän gränsen: Tre studier i journalistik om "invandrare", flyktingar och rasistisk.t vald" [News from the border: Three studies in journalism on immigrants, refugees and racist violence]. PhD diss., Gothenburg University.

Bustad, J.J. and D.L. Andrews. 2017. "Policing the void: recreation, social inclusion and the Baltimore Police Athletic league". Social Inclusion 5 (2): 241-249. doi: 10.17645/si.v5i2.904

Carbin, M. 2010. "Mellan tystnad och tal: Flickor och våld i svensk offentlig politik" [Between Silence and Speaking: Girls and Honour Violence in Swedish Public Policy]. PhD diss., Stockholm University.

Coakley, J. 2011. "Youth sports: What counts as 'positive development"'. Journal of Sport and Social Issues 35 (3): 306-324. doi: 10.1177/0193723511417311

Coakley, J. 2015. "Assessing the sociology of sport: On cultural sensibilities and the great sport myth". International Review for the Sociology of Sport 50 (4-5): 402-406. doi:

$0.1177 / 1012690214538864$

Coalter, F. 2007. A Wider Social Role for Sport: Who’s Keeping the Score? London: Routledge.

Collins, M. and Haudenhuyse, R.P. 2015. "Social exclusion and austerity policies in England: The role of sports in a new area of social polarisation and inequality?". Social Inclusion 3 (3): 5-18. doi: 10.17645/si.v3i3.54.

Crabbe, T. 2007. 'Reaching the 'hard to reach': Engagement, relationship building and social control in sport based social inclusion work". International Journal of Sport Management and Marketing 2 (1-2): 27-40. doi: 10.1504/IJSMM.2007.011388.

Dahlstedt, M. and Lozic, V. 2017. "Managing urban unres: problematising juvenile delinquency in multi-ethnic Sweden”. Critical and Radical Social Work 5 (2): 207-222. doi: 10.1332/2.

Danish, S.J. and V.C. Nellen. 1997. "New roles for sport psychologists: teaching life skills through sport at-risk youth". Quest 49: 100-113. doi: 10.1080/00336297.1997.10484226

De los Reyes, P. and D. Mulinari. 2005. Intersektionalitet: Kritiska reflektioner över (o)jämlikhetens landskap [Intersectionality: Critical reflections on the landscape of (in)equality]. Malmö: Liber. 
Eduards, M. 2012. Kroppspolitik: om Moder Svea och andra kvinnor [Body Politics: On Mother Svea and Other Women]. Stockholm: Atlas.

Ekholm, D. 2016. "Sport as a Means of Responding to Social Problems. Rationales of Government, Welfare and Social Change". PhD diss., Linköping University.

Ekholm, D., and Dahlstedt, M. 2017. "Football for Inclusion: Examining the Pedagogic

Rationalities and the Technologies of Solidarity of a Sports-based Intervention in Sweden". Social Inclusion 5 (2): 232-240. doi: 10.17645/si.v5i2.839.

Fielding-Lloyd, B. and L.J. Meân. 2008. "Standards and separatism: The discursive construction of gender in English soccer coach education". Sex Roles 58: 24-39. doi: 10.1007/s11199-0079334-x

Forde, S.D., D.S. Lee, C. Mills, and W. Frisby. 2015. "Moving towards social inclusion: Manager and staff perspectives on an award winning community sport and recreation program for immigrants". Sport Management Review 18: 126-138. doi:

Fundberg, J. 2017. "Idrottsrörelsen och samhällsnyttan - fokus på etnisk mångfald och integration" [The sports movement and the societal benefit - focus on ethnic diversity and integration]. In Idrottens sambällsnytta [The societal benefit of sports], edited by J. Faskunger, and P. Sjöblom, 118-130. Stockholm: Riksidrottsförbundet.

Goldberg, D.T. 2009. The Threat of Race, Oxford: Blackwell Publishing.

Gould, D., R. Flett, and L. Lauer. 2012. "The relationship between psychosocial development and the sports climate experienced by underserved youth". Psychology of Sport and Exercise 13: 8087. doi: 10.1016/j.psychsport.2011.07.005

Hankivsky, O., D. Grace, G.S. Hunting, O. Ferlatte. 2012. "Introduction: Why intersectionality matters for health equity and policy analysis". In An Intersectionality-Based Policy Analysis Framework, edited by O. Hankivsky, 7-32. Vancouver, BC: Institute for Intersectionality Research and Policy, Simon Fraser University.

Hartmann, D. 2016. Midnight Basketball. Race Sports, and Neoliberal Social Policy. Chicago: The University of Chicago Press.

Harvey, J., M. Lévesque, and P. Donnelly. 2007. "Sport volunteerism and social capital". Sociology of Sport Journal 24 (2), 206-223. doi: 10.1123/ssj.24.2.206

Hedenborg, S. and G. Pfister. 2017. "Introduction”. Sport in Society 20 (8), 995-997. doi: 10.1080/17430437.2016.1175134

Hylton, K. 2011. "Sport and social integration". In Routledge Handbook of Sports Development, edited by B. Houlihan, and M. Green, 100-113. London: Routledge.

Kay, T. 2006. "Daughters of Islam: Family influences on Muslim young women's participation in sport". International Review for the Sociology of Sport 41 (3-4): 357-373. doi:

10.1177/1012690207077705

Kelly, L. 2011. “'Social Inclusion' through sports-based interventions?”. Critical Social Policy 31 (1): 126-150. doi: 10.1177/0261018310385442

Knez, K., D. Macdonald, and R. Abbott. 2012. "Challenging stereotypes: Muslim girls talk about physical activity, physical education and sport". Asia-Pacific Journal of Health, Sport and Physical Education 3 (2): 109-122. doi: 10.1080/18377122.2012.700691

Larsson, J.K. 2015. Integrationen och arbetets marknad: Hur jämställdhet, arbete och annat "svensket" görs av arbetsförmedlare och privata aktörer [The market of integration and labour: how gender equality, 
labour and other "Swedish" phenomena are constructed by employment service officials and private actors]. Stockholm: Atlas.

Lawson, H.A. 2005. "Empowering people, facilitating community development and contributing to sustainable development: The social work of sport, exercise and physical education programs". Sport, Education and Society 10 (1): 135-160. doi: 10.1080/1357332052000308800

Long, J., K. Hylton, K. Spracklen, and A. Ratna. 2009. Systematic review of the literature on black and minority ethnic communities in sport and physical recreation. Leeds: Sporting Equals and the Sports Council.

Long, J., K. Hylton, and K. Spracklen. 2014. "Whiteness, blackness and settlement: Leisure and integration of new migrants". Journal of Ethnic and Migration Studies 40 (11): 1779-1797. doi: 10.1080/1369183X.2014.893189

Lykke, N. 2010. Feminist Studies: A Guide to Intersectional Theory, Methodology and Writing. New York: Routledge.

Miles, R. and Brown, M. 2003. Racism. New York: Routledge.

Mulinari, D. 2014. "Kalla mig vad fan du vill men inte invandrarförälder!” [“Call me whatever you want, but not immigrant parent"]. In Utbildning, arbete, medborgarskap [Education, work, citizenship], edited by M. Dahlstedt, F. Hertzberg, S. Urban, and A. Ålund, 189-213. Umeå: Boréa.

Nicholson, M. and R. Hoye. 2008 "Sport and social capital: An introduction". In Sport and Social Capital, edited by M. Nicholson, M. and R. Hoye, 1-20. London: Elsevier.

Ratna, A. 2011. “'Who wants to make aloo gobi when you can bend it like Beckham?' British Asian females and their racialised experiences of gender and identity in women's football". Soccer \& Society 12 (3): 382-401. doi: 10.1080/14660970.2011.568105

Raval, S. 1989. "Gender, leisure and sport: a case study of young people of south Asian descent a response”. Leisure Studies 8 (3): 237-240. doi: 10.1080/02614368700390211

Rönnbäck, J. (2015). Det är väl typiskt tjejer: om basket, kropp och femininitet. Malmö: Idrottsforum.

Spaaij, R., J. Magee, K. Farquharson, S. Gorman, R. Jeanes, D. Lusher, and R. Storr. 2016.

"Diversity work in community sport organizations: Commitment, resistance and institutional change". International Review for the Sociology of Sport. doi: 10.1177/1012690216654296

Spracklen, K., J. Long, and K. Hylton. 2015. "Leisure opportunities and new migrant communities: challenging the contribution of sport”. Leisure Studies 34 (1): 114-129. doi: 10.1080/02614367.2014.939989

Salonen, T., ed. 2011. Hela staden: Social hallbarhet eller desintegration [The whole city: Social sustainability or disintegration]. Umeå: Boréa.

Sernhede, O., C. Thörn, and H. Thörn. 2016. “The Stockholm uprising in context: Urban social movements and the rise and demise of the Swedish welfare state city". In Urban Uprisings: Challenging Neoliberal Urbanism in Europe, edited by M. Mayer, C. Thörn, and H. Thörn, 149-173. Basingstoke: Palgrave Macmillan.

Statistics Sweden. 2014. Segregation i Stockholm län [Segregation in Stockholm County]. Demografisk rapport 2014:09. Stockholm: SCB.

Stigendal, M. 2016. Sambällsgränser: ojämlikhetens orsaker och framtidsmöjligheterna $i$ en storstad som Malmö [Boundaries in society: the causes of inequality and future opportunities in a big city such as Malmö]. Stockholm: Liber. 
Strandbu, A. 2002. "Idrettens betydning som flerkulturell integrasjonsarena" [The meaning of sports as a multicultural arena of integration]. In Idrettens bevegelser [The movement of sports], edited by $\varnothing$. Seippel, 123-153. Oslo: Novus.

Strandbu, A. 2005. "Identity, embodied culture and physical exercise. Stories from Muslim girls in Oslo with immigrant backgrounds". Young 13 (1): 27-45. doi: 10.1177/1103308805048751

Svender, J. 2012. "Så gör(s) idrottande flickor: iscensättningar av flickor inom barn- och ungdomsidrotten" [Discursive constructions of girls in a sports initiative: How sporting girls are represented and the working of power]. PhD diss., Stockholm University.

Swedish Research Council. (2011). 'Good research practice'. Available at: http://www.vr.se/download/18.3a36c20d133af0c1295800030/1340207445948/Good+Research +Practice+3.2011_webb.pdf [Accessed 28 April 2018].

Tigervall, C. 2005. "Folkhemsk film: Med 'invandraren' i rollen som den sympatiske Andre" [Film representations of the sympathetic 'immigrant']. PhD diss., Umeå University.

Tolvhed, H. 2015. På damsidan. Femininitet, motstand och makt $i$ svensk idrott 1920-1990 [On the women's side. Femininity, resistance and power in Swedish sports 1920-1990]. Göteborg: Makadam.

Vandermeerschen, H. and J. Scheerder. 2017. "Sport managers'perspectives on poverty and sport: The role of local sport authorities". Sport Management Review 20 (5): 510-521. doi: 10.1016/j.smr.2017.02.002

Vandermeerschen, H., J. Meganck, J. Seghers, S. Vos and J. Scheerder, J. 2017. "Sports, poverty and the role of the voluntary sector. Exploring and explaining nonprofit sports clubs' efforts to facilitate participation of socially disadvantaged people". Voluntas 28 (1): 307-334. doi: $10.1007 / \mathrm{s} 11266-016-9799-8$

Walseth, K. 2006. "Young Muslim women and sport: the impact of identity work". Leisure Studies 25 (1): 75-94. doi: 10.1080/02614360500200722

Walseth, K. 2008. "Bridging and bonding social capital in sport - experiences of young women with immigrant background". Sport, Education and Society 13 (1): 1-17. doi: 10.1080/13573320701780498

Walseth, K. 2016. "Sport within muslim organizations in Norway: ethnic segregated activities as arena for integration”. Leisure Studies 35 (1): 78-99. doi: 10.1080/02614367.2015.1055293

Walseth, K. and K. Fasting. 2004. "Sport as a means of integrating minority women". Sport in Society 7 (1): 109-129. doi: 10.1080/1461098042000220218

Walseth, K. and Å. Strandbu. 2014. "Young Norwegian-Pakistani women and sport. How does culture and religiosity matter?” European Physical Education Review 20 (4): 489-507. doi:

10.1177/1356336X14534361 